\title{
Effect of Taper Angle on Flow and Stress in Conical Shell Fluid Mixers
}

\author{
Mustafa Murat YAVUZ* \\ Department of Mechanical Engineering, Izmir Democracy University, İzmir, 35140, Turkey \\ (ORCID: 0000-0002-5892-0075)
}

\begin{abstract}
Hollow cylindrical flow mixers achieve a homogeneous mixture with less pressure loss and higher momentum. However, the low volume of the mixer due to the hollow creates high pressure effects and mechanical stresses on the mixer. In this study, the stresses formed on the mixer by considering the flow and thermal effects of fluids in a conical cylinder mixer at different temperatures were examined. The effect of taper angle has been studied. In the examinations carried out using the finite element method, a verification study was first made, and solution sensitivity was determined. Water as fluid in standard conditions and common steel properties as cylinder material were used. Plate thickness was chosen to be $1 \mathrm{~mm}$. It seems more appropriate to use a non-conical straight model to achieve thermal equilibrium. The taper angle reduced the high velocity region created by the fluid entering the mixer. Stress concentrations were observed at the supports and a lower and decreasing stress distribution was obtained for the conical mixer while it was constant for the straight cylinder in the other regions.
\end{abstract}

Keywords: Cylindrical Mixer, Taper Angle, Von-Mises Stress, Finite Element Analysis

\section{Konik Gövdeli Akışkan Karıştırıcılarda Konik Açının Akış ve Gerilme Üzerindeki Etkisi}

\begin{abstract}
Öz
İçi boş silindirik akış karıştırıcıları daha az basınç kaybı ve daha yüksek momentum ile homojen bir karışım elde edilmesini sağlar. Bununla birlikte, oyuk nedeniyle karıştırıcının düşük hacmi karıştırıcı üzerinde yüksek basınç etkileri ve mekanik gerilmeler yaratır. Bu çalışmada, konik silindirli bir karıştırıcıda akışkanların farklı sıcaklıklarda akış ve ısıl etkileri dikkate alınarak karıştırıcı üzerinde oluşan gerilmeler incelenmiştir. Konik açının etkisi incelenmiştir. Sonlu elemanlar yöntemi kullanılarak yapılan incelemelerde öncelikle bir doğrulama çalışması yapılmış ve çözüm hassasiyeti belirlenmiştir. Standart koşullarda akışkan olarak su ve silindir malzemesi olarak yaygın çelik özellikleri kullanılmıştır. Levha kalınlığı $1 \mathrm{~mm}$ olarak seçilmiştir. Termal dengenin sağlanması için düz silindir şeklinde bir model kullanmak daha uygun görünmektedir. Koniklik açısı, miksere giren akışkanın oluşturduğu yüksek hız bölgesini azaltmıştır. Bağlantı yerlerinde gerilme yoğunlukları gözlenmiş ve diğer bölgelerde düz silindir için sabit iken konik karıştırıcıda daha düşük ve azalan bir gerilme dağılımı elde edilmiştir.
\end{abstract}

Anahtar kelimeler: Silindirik Karıştırıcı, Konik Açı, Von-Mises Gerilmesi, Sonlu Eleman Analizi

\section{Introduction}

The mixing of materials and phases at different temperatures is carried out with various mixing units. The desired mixing of two or more components depends on the characteristics of the unit used (geometry, active-passive mixing, etc.). Although mixing performance is a priority, it is desired that the mixers complete the mixture in less unit area and create less loss in flow pressure. Studies in the literature were grouped according to mixture materials and methods. Commonly, powder-gas and liquid-liquid mixtures have been researched and different mixers have been designed. Jet angle effect was investigated in a jet mixer up to $45^{\circ}$ and optimum angle was determined at $35^{\circ}$ [1]. The CFD simulation of cement mixer was analysed and the results obtained for use in future cement mixer designs were highlighted [2]. The cyclone type mixers were examined considering the recirculation and cavitation

"Corresponding author: murat.yavuz@idu.edu.tr

Received: 04.05.2021, Accepted:13.09.2021 
locations classified as dead zones [3]. It has been observed that the pressure loss in the water causes circulation, dead zones and cavitation according to the eddy movement. DEM (discrete element method) and CFD methods were used together to investigate the particle behaviour in a static mixer and the optimization of the mixer geometry to improve the mixing quality was discussed [4]. A comparison study was investigated for the performance of static mixers, which takes into account the quality of the mix as well as energy efficiency and compactness [5]. Residence time distribution was simulated by regression method for helical static mixers [6]. The simulation results were consistent with experimental results, and the model could simulate different volumetric flow rates. The efficiency of an axial mixer was investigated using CFD and the pressure drop was reduced by up to $40 \%$ as a result of applied geometric modification [7]. A static mixer under granular flow was investigated with the combined DEM/CFD methods and as a result, it was seen that the mixing elements in the mixer had a more dominant effect than the material types used in the mixing process [8]. Newtonian and non-Newtonian fluids were studied for in-line high shear mixers [9]. In the results, non-Newtonian shear thinning powerlaw fluids had a higher strain rate at the mixing head than Newtonian fluids, resulting in larger dead zones. The mixing process of granular materials was investigated for a rotary drum by considering the rotational speed and drum length, and it was determined that the side wall effect and the drum length were effective [10]. The height of the mixer was found to be a dominant effect in the mixes and appropriate modifications were applied for the performance analysis of a helical ribbon mixer [11]. An optimal hydrocyclone design was developed using CFD analysis and 3D printed model, and as a result, a rapid production structure was obtained with a $10 \%$ improvement [12]. Large eddy simulation of three different high shear mixers with circular, square and inclined was investigated under a rotor speed of $4000 \mathrm{rpm}$ [13]. It was observed that the inclined stator head of the mixer had performed better and it was determined that reducing the stator hole size had required less energy. A high-efficiency vortex (HEV) mixer was used to mix the two-phase flow, and in the observations, flow fluctuations occurred near the mixer wall [14]. In this case, the turbulence dispersion velocity reached the highest value. Fluid flow and heat transfer analyses of Kenics mixer were investigated with constant heat flux through the walls and the mixer increased the Nusselt number up to 50\% [15]. A static mixer was optimized by using different internal grids [16]. The measurement performance of numerical methods in mixers was examined and flow vectors were obtained in detail [17]. The inclined plane angle of tubular photobioreactors connected to static mixers was investigated and it was observed that mass transfer increased as a result of increasing the angle [18]. 3 different water inlets were examined for a solar water tank filling and the appropriate water inlet were determined to obtain a more homogeneous structure in the hot-cold water mixture [19]. Mixing performance of 2 and 4 misaligned inlet t-mixers were examined and, in the results, it was recommended that the 4-input mixer was not efficient, and that 2-input mixer should be preferred instead [20]. A gradually curved channel was incorporated into a micro mixer and four different mixers were designed [21]. It was observed that the stepped curved channel mixer had $20 \%$ better mixing performance than the normal curved mixer but caused $50 \%$ higher pressure drop. T, $\mathrm{O}$ and $\mathrm{H}$-micromixers were used instead of straight tube mixers by using slicing and recombination (SAR) method and the highest mixing efficiency was achieved by using H-micromixer [22]. The cause of thermal fatigue crack by considering the temperature fluctuations during the mixing of hot and cold fluids were investigated in tee pipe connections [23]. On the inner surface of the main pipe where the mixture joined, the local stress and temperature fluctuation range was measured as high. Thermal fatigue crack formation potential was investigated by considering the temperature fluctuation frequencies of the fluid close to the surface edges in mixing tees where hot and cold fluid mixtures take place [24]. A tmixer with a non-aligned inlet was examined considering the structure of the mixer inlet and its asymmetric flow [25]. Increased Reynolds number was improved mixing performance in contrast to normal t-mixers. Generally, the performance of the mixture was examined in the studies examined in the literature review. In these examinations, the inlet-outlet mixing performance was examined. An investigation of a cylinder with taper angle designed for hot-cold fluid mixture has not been detected and detailed flow observation and stress analysis have been made on this subject.

\section{Material and Method}

Numerical methods enable the mathematical models of systems to be examined within appropriate boundary conditions and they were used in the flow and mechanical analysis of conical mixer. 
Computational fluid dynamics (CFD) for flow and finite element method (FEM) for structural analysis were used. Idealized models were created, and numerical models were obtained from these models. The numerical model was included the grid or finite element structure of the geometric model, and the solutions were realized over the created grid or finite elements. Ansys Workbench package software was used in analysis. Before the examination of the conical cylinder, basic models with similar structure and known analytical solution were analysed numerically and the results were compared.

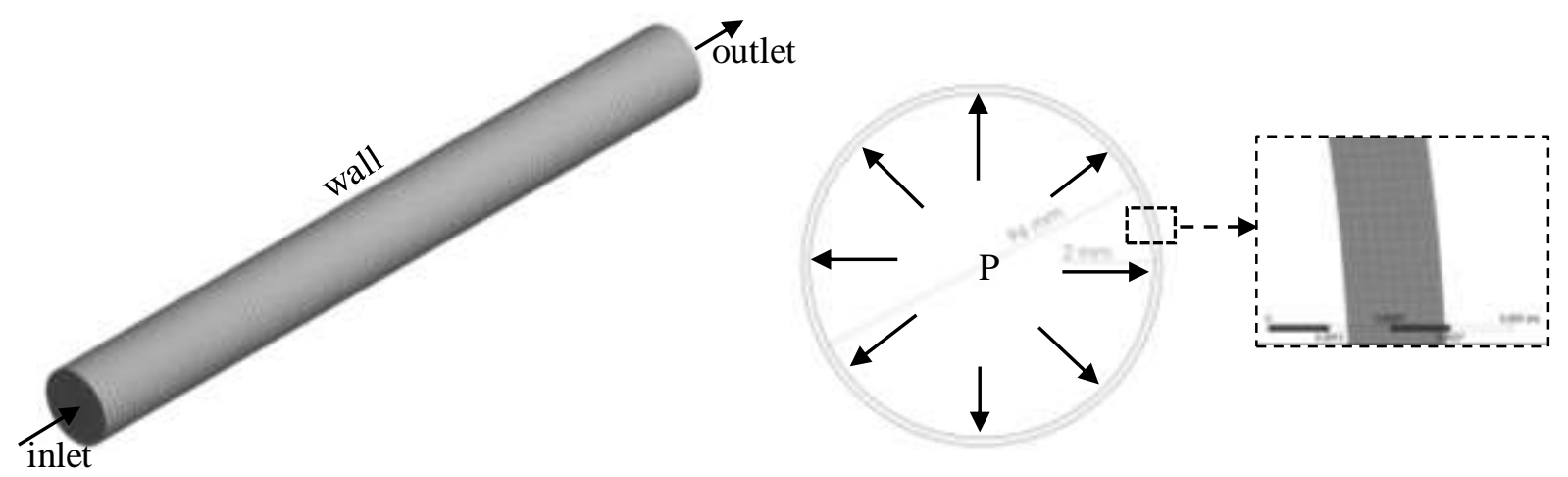

Figure 1. CFD model of a straight pipe (a) and FEM model of thin cylinder (b)

In Fig. 1, a numerical model of a straight pipe for precision of flow solution and a thin-walled pressurized cylinder for the precision of mechanical solution were shown. In the flow solution, the pipe diameter (D) was modelled as 0.1 meter and a length of $10 \mathrm{D}$. With standard properties, water (density of $998.2 \mathrm{~kg} / \mathrm{m}^{3}$ and viscosity of $0.001003 \mathrm{~kg} / \mathrm{ms}$ ) was chosen as the fluid. Fluid velocity [26-27] for the Reynolds number 10.000 was calculated by Eq. 1 and found to be $0.1 \mathrm{~m} / \mathrm{s}$. In-pipe pressure difference obtained from the energy equation was shown in Eq. 2. K-epsilon turbulence model has been one of the most common used models in literature, was used in this analysis. The stress equation for the thin-walled cylinder model, whose finite element model [28] was shown, in Eq. 3. Steel (E=200 GPa, $v=0.3$ ) was used as shell material. $1000 \mathrm{~Pa}$ pressure was applied. $\mathrm{P}$ is internal pressure; $\mathrm{t}$ is thickness of thin cylinder and $\mathrm{r}$ is the mean or maximum radius of thin cylinder.

$$
\begin{aligned}
R e & =\frac{\rho \cdot v \cdot D}{\mu} \\
\Delta P & =f \frac{L}{D} \frac{\rho \cdot V^{2}}{2} \\
\sigma_{t} & =\frac{P \cdot r}{t}
\end{aligned}
$$
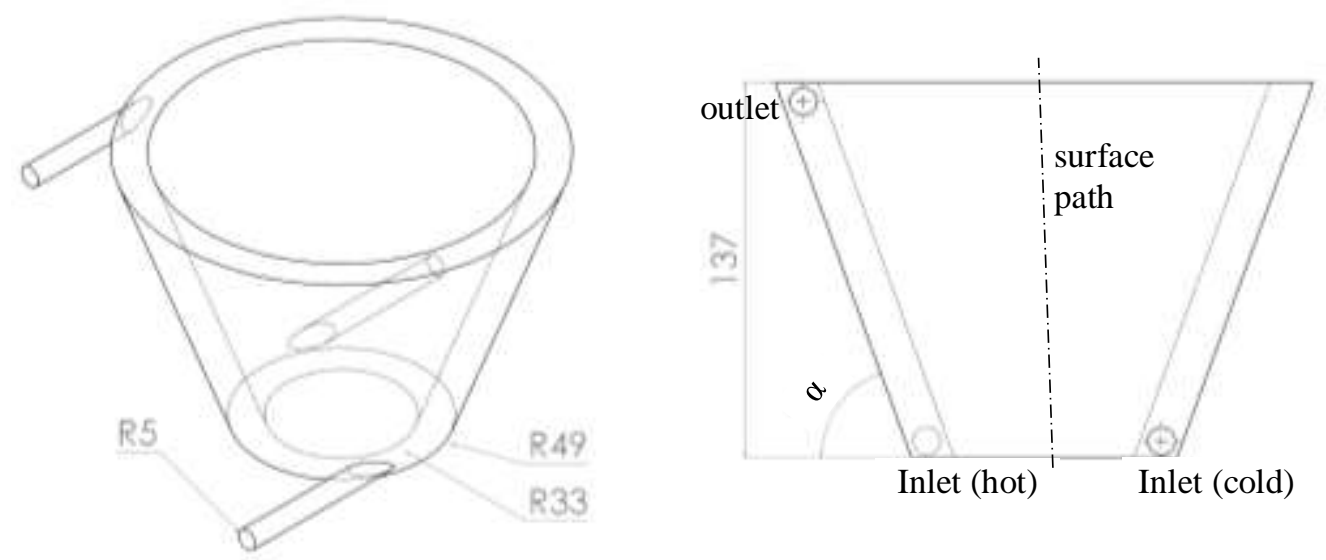

Figure 2. Isometric and front view of conical cylinder mixer model (sizes are in $\mathrm{mm}$ ) 
The conical cylinder mixer model was shown in Fig. 2 and its geometric properties were given. While the base geometry and dimensions were remained the same, the inner and outer radii forming the upper surface changed linearly with the taper angle used. Hot and cold fluids were sent from the cylinder side lower surfaces mutually. There has been an outlet on the side upper surface. Hot water has a temperature of $333 \mathrm{~K}$ and cold water has a temperature of $300 \mathrm{~K}$. Environmental effects and heat transfer loss were neglected. Inlet velocities were $1 \mathrm{~m} / \mathrm{s}$. Flow solutions were examined with an average of 1000 time steps with time intervals of $2 \mathrm{~ms}$ depending on time. The thickness of the mixer plate was $1 \mathrm{~mm}$ and the upper and lower outer corners of the cylinder were fixed for structural analysis.

\section{Results and Discussion}

For smooth pipe, the friction coefficient (f) is 0.032 in the non-turbulent condition. The analytical solution of pressure drop was $1.597 \mathrm{~Pa}$ from Eq. 2. The CFD solution of straight pipe in Fig. 1 has a pressure drop of 1.647 Pa. Flow solution difference was \%3.03. The tangential stress calculated using Eq. 3 was found to be 25.000 Pascals. In the finite element solution used for structural analysis, the stress was obtained as $24.590 \mathrm{~Pa}$ and the difference was around \%1.7. The numerical analysis can be applied for general solution of flow and structural analysis of cylinder mixer model.

Velocity profiles were shown according to different taper angles $(\alpha)$ for hot and cold fluid inlets in Fig. 3. The widening of the conic section was shown inversely with the taper angle $(\alpha)$. A plane perpendicular to the cylinder center and located at the fluid inlets was used to observe the flow state. The effect of the conical angle $(\alpha)$ has been clearly visible on the inlet pipes and inside the conical chamber. Mixers were divided into 3 basic classes in macro, meso and microstructures with their structures and mixture material properties, and the classification was determined according to the structures formed during mixing [29-30]. The dominance of the eddy structure and the formation of a mixture in the form of diffusion have been known as meso mixing [31]. Although mixture contours were contained time-dependent averages, it was understood that the structure of the mixture was in macro mixing due to the formation of flow bands in Fig. 3. The smooth cylindrical structure at different taper angles was seemed to be the main factor in the formation of the macro mixing.

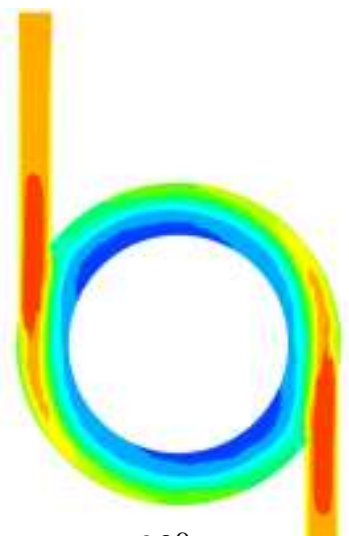

$\alpha=90^{\circ}$

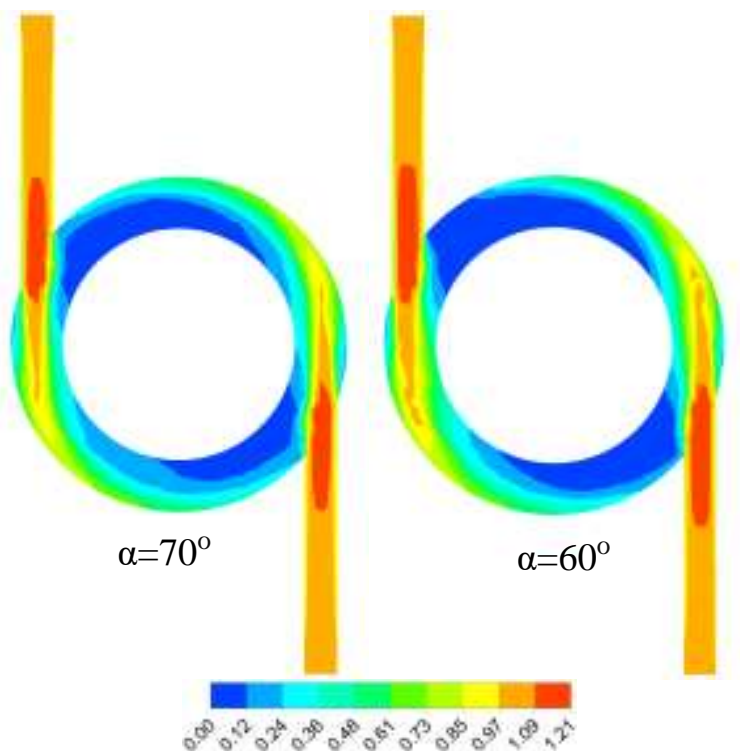

Figure 3. Velocity contours at the inlet location

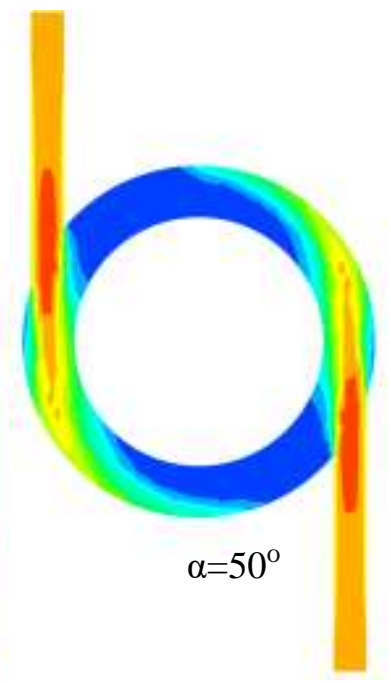

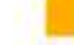


higher flow velocities closer to the outer wall and more dominant on the pipe-mixer joints due to the momentum effects.
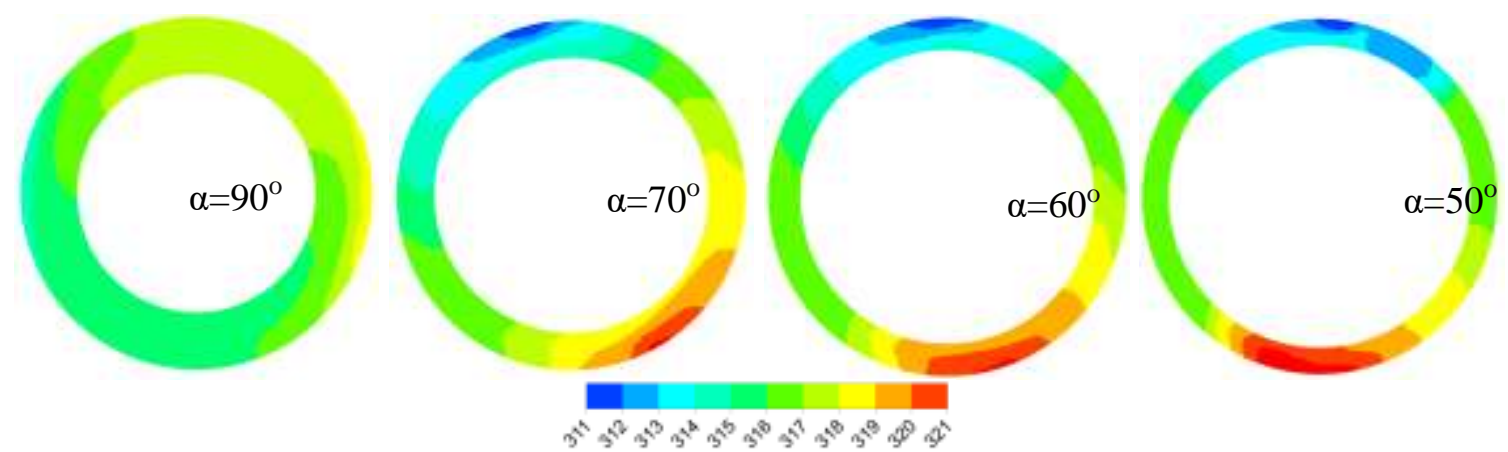

Figure 4. Temperature contours at the middle section of the mixer

In Fig. 4, temperature contours in the mixer were shown from a plane formed at half the height of the cylinder. It was observed that the mixture of hot and cold liquid still did not reach thermal equilibrium. The temperature in this section was between the highest $333 \mathrm{~K}$ and the lowest $300 \mathrm{~K}$, and the mixing process has been still ongoing. It can be said that one of the reasons for this is the accumulation of fluids close to the outer wall of the mixer as a result of the momentum effect. Momentum showed centrifugal force effect in liquids rotating in a circular mixer and increased the fluid velocity near the outer wall of the mixer. There is less temperature difference in the vertical cylindrical mixer with a $\alpha=90^{\circ}$ taper angle. Increasing the taper angle compared to the straight cylindrical mixer caused an increase in the temperature range. In addition, the hot and cold flow region has been more pronounced. The straight cylindrical mixer performed better in terms of mixer performance and flow conditions. The temperature fluctuation was seen to be higher at the highest taper angle $\left(\alpha=50^{\circ}\right)$. This may cause temperature and local stress effects to dominate [23]. A more uniform temperature mixture would exhibit less temperature fluctuation behaviour in a right-angled $\left(\alpha=90^{\circ}\right)$ mixer [24]. As a result of the interaction of high and low momentum in the fluid structure, large-scale heat transfer has occurred [32] and a macro-structured mixture has formed in the results.

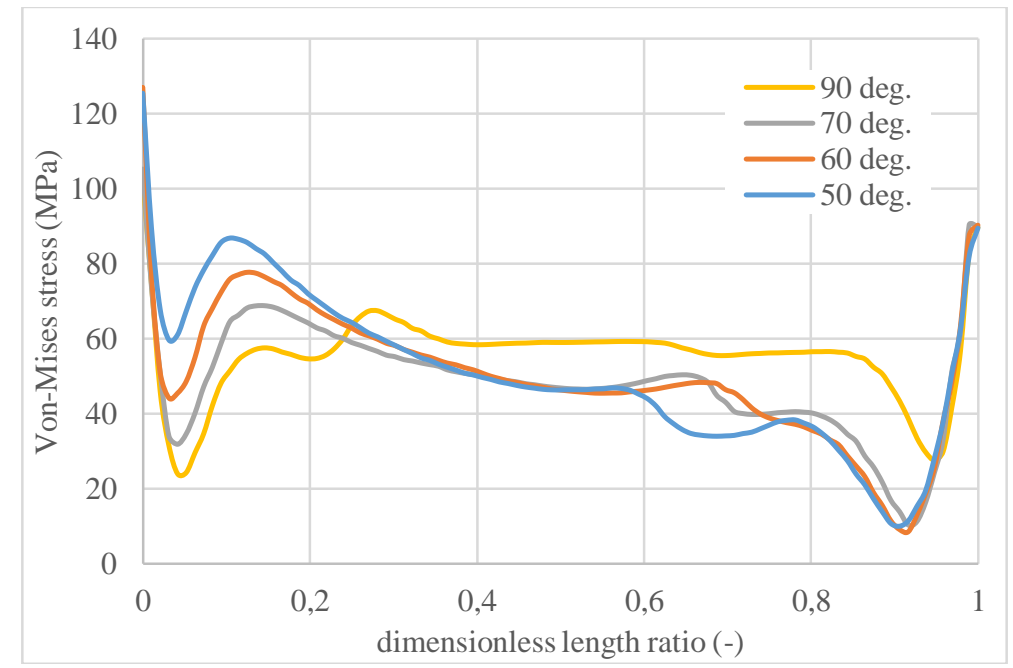

Figure 5. Von-Mises stress distribution at the surface path

Stress results were shown in Fig. 5 on the conical surface according to the Von-Mises stress criterion. The results showed stress concentrations due to the support of the lower and upper surfaces of the cylinder. The stress drop after the support stress concentration was due to the deformation of the outer plate in a limited region. The average stress value of $60 \mathrm{MPa}$ was occurred in the straight cylinder body. The usage of taper angle caused high stresses where the dimensionless length ratio was 0.1 under the effect of the lower pipe joint. The lowest stress occurred when the taper angle was $70^{\circ}$ and the highest stress occurred when it was $50^{\circ}$. In the conical results, in the range where the dimensionless length ratio 
was 0.3 and 0.95 , the stress values were lower and showed a decreasing behaviour compared to the straight cylinder. It can be said that the $70^{\circ}$ taper angle model was the most ideal according to the stress results.

\section{Conclusion}

In this study, the flow-temperature and stress conditions of a conical mixer with a cavity in the centre were investigated according to the taper angle. There were few studies on this subject in the literature and there was more basic information on conical separators. In the study, flow-temperature and stresses occurring in the mixer body were investigated interactively. First, a verification study was carried out in the model using the numerical analysis method. Flow was sent from two inlets at $300 \mathrm{~K}$ and $333 \mathrm{~K}$ under ideal flow conditions and the mixture was discharged from a single outlet.

i. As a result of the examination, it was seen that the taper angle has a dominant effect on the results

ii. Increasing the taper angle compared to the straight cylindrical mixer caused an increase in the temperature range and farther from thermal equilibrium

iii. The taper angle reduced the high velocity region caused by the fluids entering the mixer to a certain extent

iv. Stress concentration locations were determined in the support regions

v. As a result of the straight cylinder, the stress was almost constant on the cylinder surface, while it exhibited a decreasing behaviour in conical angle models and gives a lower stress result. Therefore, when examined mechanically, the ideal result was obtained in the $70^{\circ}$ taper angle model

\section{Author's Contributions}

All contributions belong to the author in this paper.

\section{Statement of Conflicts of Interest}

No potential conflict of interest was reported by the author.

\section{Statement of Research and Publication Ethics}

The author declares that this study complies with Research and Publication Ethics.

\section{References}

[1] Farbod A., Moghaddas J.S., Shokrgozar M. 2010. CFD simulation and experimental investigation of a jet mixer: effect of flow rate and jet angle on mixing time using the RSM model. 13th Iranian National Chemical Engineering Congress, 25-28 October, Kermanshah, Iran.

[2] Shuiping L., Xiaotian L., Lugang S. 2011. Simulation of the flow field of cement mixer based on numerical methods. Advances in Systems Science and Applications, 11 (3-4): 315-321.

[3] Kölbl A., Kraut M., Wenka A. 2011. Design parameter studies on cyclone type mixers. Chemical Engineering Journal, 167: 444-454.

[4] Jovanović A., Pezo M., Pezo L., Lević L. 2014. DEM/CFD analysis of granular flow in static mixers. Powder Technology, 266: 240-248.

[5] Meijer H.E.H., Singh M.K., Anderson P.D. 2012. On the performance of static mixers: a quantitative comparison. Progress in Polymer Science, 37 (10): 1333-1349.

[6] Akila R., Balu K. 2015. Regression model for fluid flow in a static mixer. Chemical Engineering Research Bulletin, 18: 23-29.

[7] Hanada T., Kuroda K., Takahashi, K. 2016. CFD geometrical optimization to improve mixing performance of axial mixer. Chemical Engineering Science, 144: 144-152.

[8] Pezo L., Pezo M., Jovanović A., Kosanić N., Petrović A., Lević L. 2016. Granular flow in static mixers by coupled dem/cfd approach. Hemijska Industrija, 70 (5): 539-546. 
[9] Zhang C., Gu J., Qin H., Xu Q., Li W., Jia X., Zhang J. 2017. CFD analysis of flow pattern and power consumption for viscous fluids in in-line high shear mixers. Chemical Engineering Research and Design, 117: 190-204.

[10] Liu X., Hu Z., Wu W., Zhan J., Herz F., Specht E. 2017. DEM study on the surface mixing and whole mixing of granular materials in rotary drums. Powder Technology, 315: 438-444.

[11] Mihailova O., Mothersdale T., Rodgers T., Ren Z., Watson S., Lister V., Kowalski A. 2018. Optimisation of mixing performance of helical ribbon mixers for high throughput applications using computational fluid dynamics. Chemical Engineering Research and Design, 132: 942-953.

[12] Vega-Garcia D., Brito-Parada P.R., Cilliers J.J. 2018. Optimising small hydrocyclone design using 3d printing and cfd simulations. Chemical Engineering Journal, 350: 653-659.

[13] Vikash V.K. 2019. Turbulent statistics of flow fields using large eddy simulations in batch high shear mixers. Chemical Engineering Research and Design, 147: 561-569.

[14] Vikhansky A. 2020. CFD modelling of turbulent liquid-liquid dispersion in a static mixer. Chemical Engineering \& Processing: Process Intensification, 149: 107840.

[15] Abotsi O.Y.W., Kizito J.P. 2020. Numerical study of heat transfer augmentation in an axially rotating pipe equipped with kenics mixer. Case Studies in Thermal Engineering, 21: 100695.

[16] Singh M.K., Anderson P.D., Meijer H.E.H. 2009. Understanding and optimizing the smx static mixer. Macromol. Rapid Commun., 30: 362-376.

[17] Jilisen R.T.M., Bloemen P.R., Speetjens M.F.M., Three-dimensional flow measurements in a static mixer, AIChE Journal, 59(5), 1746-1761, 2013.

[18] Ugwu C.U., Ogbonna J.C., Tanaka H. 2002. Improvement of mass transfer characteristics and productivities of inclined tubular photobioreactors by installation of internal static mixers. Appl Microbiol Biotechnol, 58: 600-607.

[19] Shah L.J., Furbo S. 2003. Entrance effects in solar storage tanks. Solar Energy, 75: 337-348.

[20] Ansari M.A., Qamareen A., Ansari M.Z. 2019. Mixing of fluids in vortex t-mixer with two and four nonaligned inlet microchannels. IOP Conf. Series: Materials Science and Engineering, 691: 012030.

[21] Sheu T.S., Chen S.J., Chen J.J. 2012. Mixing of a split and recombine micromixer with tapered curved microchannels. Chemical Engineering Science, 71: 321-332.

[22] Nimafar M., Viktorov V., Martinelli M. 2012. Experimental comparative mixing performance of passive micromixers with h-shaped sub-channels. Chemical Engineering Science, 76: 37-44.

[23] Miyoshi K., Kamaya M., Utanohara Y., Nakamura A. 2016. An investigation of thermal stress characteristics by wall temperature measurements at a mixing tee. Nuclear Engineering and Design, 298: 109-120.

[24] Utanohara Y., Nakamura A., Miyoshi K., Kasahara N. 2016. Numerical simulation of long-period fluid temperature fluctuation at a mixing tee for the thermal fatigue problem. Nuclear Engineering and Design, 305: 639-652.

[25] Ansari M.A., Kim K., Anwar K., Kim S.M. 2012. Vortex micro t-mixer with non-aligned inputs. Chemical Engineering Journal, 181- 182: 846-850.

[26] Versteeg H.K., Malalasekera, W. 2007. An introduction to computational fluid dynamics, 2nd edition. Pearson Education Limited.

[27] White F.M. 2016. Fluid mechanics 8th edition, McGraw Hill.

[28] Budynas R., Nisbett K. 2020. Shigley's mechanical engineering design 11th edition, McGraw Hill.

[29] Baldyga J., Pohorecki R. 1995. Turbulent micro mixing in chemical reactors - a review. Chem. Eng. J., 58(2): 183-195.

[30] Bourne J.R. 2003. Mixing and the selectivity of chemical reactions. Org. Process Res. Dev., 7(4): 471-508.

[31] Gradl J., Peukert W., Characterization of micro mixing for precipitation of nanoparticles in a tmixer, 105-124, Micro and Macro Mixing, Analysis, Simulation and Numerical Calculation, Springer, 2010.

[32] Ghanem A., Lemenand T., Valle D.D., Peerhossaini H. 2014. Static mixers: mechanisms, applications, and characterization methods a review. Chemical Engineering Research and Design, 92: 205-228. 